\title{
Early and midterm results in anatomic repair of Ebstein anomaly
}

\author{
Qingyu Wu, MD, ${ }^{a}$ Zhixiong Huang, MD, ${ }^{\mathrm{b}}$ Guangyu Pan, MD, ${ }^{a}$ Lianyi Wang, MD, ${ }^{a}$ Lei Li, MD, ${ }^{\mathrm{a}}$ and Hui Xue, MD
}

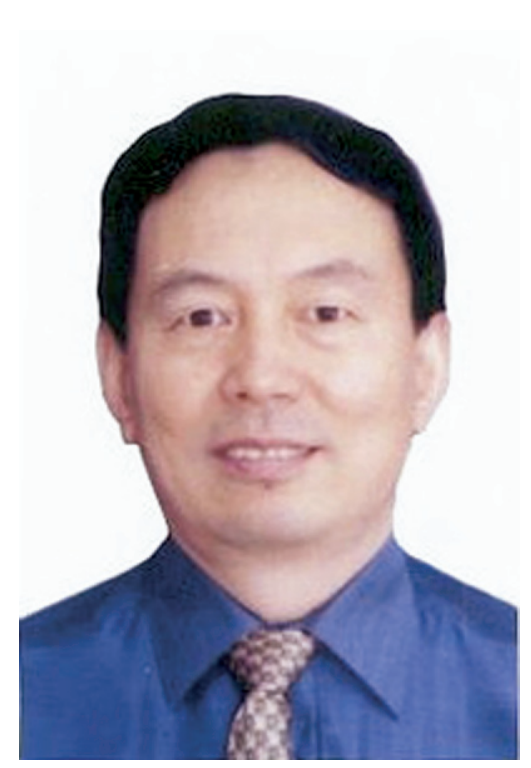

Dr Wu
From the Heart Center, First Hospital of Tsinghua University, ${ }^{a}$ Beijing, China; and the Department of Cardiovascular Surgery, Cardiovascular Institute, Fu Wai Hospital, Chinese Academy of Medical Science, Peking Union Medical College, ${ }^{b}$ Beijing, China.

Read at the Eighty-seventh Annual Meeting of The American Association for Thoracic Surgery, Washington, DC, May 5-9, 2007.

Received for publication May 7, 2007; revisions received Aug 22, 2007; accepted for publication Aug 30, 2007.

Address for reprints: Qingyu Wu, MD, Heart Center, First Hospital of Tsinghua University, Beijing, China (E-mail: wuqingyu@mail. tsinghua.edu.cn).

J Thorac Cardiovasc Surg 2007;134:1438-42 $0022-5223 / \$ 32.00$

Copyright (C) 2007 by The American Association for Thoracic Surgery

doi:10.1016/j.jtcvs.2007.08.019
Objective: We report the results of surgical treatment of Ebstein anomaly during a 10-year period, especially with an anatomic repair technique that restores to near normal anatomic and physiologic function of the tricuspid valve and the right ventricle.

Methods: Between December 1997 and December 2006, 83 consecutive patients aged 9 months to 52 years underwent operation for Ebstein anomaly. Among them, 78 underwent the anatomic repair technique (male 39). Tricuspid incompetence was moderate in 22 patients and severe in 56 patients. The main surgical technique includes excision of the atrialized right ventricle, detachment and repair of the leaflet, transposition of the leaflet, and anulus plication of the tricuspid valve. In some patients in whom the septal leaflet was severely hypoplastic or absent, a new leaflet was created with autologous pericardium. Biventricular repair was not performed in 5 patients with very severely hypoplastic tricuspid valves and poor right ventricular function.

Results: All patients survived and recovered uneventfully. For the 78 patients who underwent anatomic repair, postoperative echocardiography showed that tricuspid incompetence disappeared in 65 patients and was mild in 13 patients. Right ventricular function was good. Patients have been doing well during a mean follow-up of 46 months ( 2 months to 9 years). The latest follow-up echocardiograms showed that tricuspid incompetence was eliminated in 55 patients and was mild in 17 , moderate in 3 , and severe in 3 . The 5 patients with a total cavopulmonary connection procedure and one-and-one-half-ventricle correction procedure are also doing well.

Conclusions: Satisfactory early and midterm results can be achieved with the anatomic repair technique to correct Ebstein anomaly. Tricuspid valve replacement can be avoided in most patients.

$\mathrm{E}$ bstein anomaly refers to a condition with downward displacement of the septal and posterior leaflets, occasionally with isolated anterior leaflet of the tricuspid valve into the right ventricle, leaving an atrialized portion of the right ventricle. Operations for Ebstein anomaly include tricuspid valve repair and replacement. The long-term results of tricuspid valve replacement are not satisfactory because of anticoagulant-related complications concerning mechanical prosthetic valves or calcification and degeneration of bioprosthetic valves. Several kinds of repair techniques with good results have been reported. ${ }^{1-4}$ We report our experience in the surgical treatment of Ebstein anomaly with the anatomic repair technique.

\section{Patients and Methods}

Between December 1997 and December 2006, 83 consecutive patients with Ebstein anomaly underwent operation, and 78 of them were treated with the anatomic repair technique. There were 40 male and 43 female patients aged 9 months to 52 years (17.9 \pm 7.2 years). Patients were in New York Heart Association functional class II $(n=24)$ or functional class III $(n=$ 
59). Six patients had cyanosis during exercise and 7 had cyanosis at rest. Electrocardiograms indicated right ventricular hypertrophy in 9 patients, complete right bundle branch block in 18, atrial fibrillation in 2, and Wolff-Parkinson-White syndrome in 5; 1 patient had undergone successful catheter ablation of his abnormal pathway before the operation. The preoperative cardiothoracic ratio ranged from 0.46 to 0.76 (mean, 0.63 ). The diagnosis was established by preoperative echocardiography in all patients. Tricuspid incompetence was moderate in 22 patients and severe in 56. In 1 patient the diagnosis of double-outlet right ventricle and pulmonary stenosis was made by ultrasonic cardiography and cardioangiography. The diagnosis was confirmed and an extra diagnosis of Ebstein anomaly was added on the basis of the operative findings. Associated complicated lesions masked the Ebstein anomaly in this patient.

\section{Surgical Procedure}

All operations were done with the patient under general anesthesia with total cardiopulmonary bypass, aortic and bicaval cannulation, and systemic hypothermia $\left(25^{\circ} \mathrm{C}\right.$ $30^{\circ} \mathrm{C}$ ). The mean aortic crossclamp time was $60 \pm 21$ minutes, and the mean bypass time was $100 \pm 34$ minutes. After the aorta was crossclamped, cardioplegic solution was administered through the aortic root. The right atrium was opened parallel to the atrioventricular groove, and the tricuspid valve was inspected. The main surgical technique includes excision of the atrialized right ventricle, detachment and repair of the leaflet, transposition of the leaflet, and anulus plication of the tricuspid valve, as described before. ${ }^{5}$ In 22 patients with adequate-sized posterior and septal leaflets, the detached leaflets were reattached to a position just below the natural annulus with their corresponding papillary muscle reimplanted. In 30 patients, a "new leaflet" was made by using autologous maldeveloped posterior and septal leaflet tissue. In 26 patients the septal leaflet was severely hypoplastic, appearing like tiny membranous tissue remnants of the original leaflet. For these patients, a piece of fresh autologous pericardium was fashioned as the "new septal leaflet" by suturing the base of the "new leaflet" to a position just below the natural annulus. Autologous tissue and a pericardiac strip were used to make a new chordae, and the abnormal muscle band was freed to substitute for papillary muscle if necessary. Part of the right atrial wall was also resected. There were 2 patients with extremely uncommon conditions: the isolated anterior leaflet was displaced downward and the large atrialized right ventricle was positioned anteriorly, whereas the septal and posterior leaflets were reasonably developed and in the normal position. These conditions were also corrected with the anatomic repair technique. Associated procedures included atrial septal defect repair in 18 patients, closure of a patent foramen ovale in 13, ventricular septal defect repair in 3, closure of a patent ductus arteriosus plus ventricular septal defect repair in 2, relief of right ventricular outflow tract obstruction in 8 , closure of a patent ductus arteriosus plus relief of right ventricular outflow tract obstruction in 1, and Rastelli operation in 1. Biventricular repair was not performed in 5 patients owing to severe hypoplasia of all three leaflets of the tricuspid valve and very poor right ventricular function. Among them, a total cavopulmonry connection procedure was performed in 4 patients and oneand-one-half-ventricle repair in 1 .

An intraoperative transesophageal echocardiogram was obtained routinely to assess the tricuspid valve and ventricular function after the repair.

\section{Results}

There were neither early deaths nor significant postoperative complications. No patient had transient or permanent third-degree atrioventricular block and none needed tricuspid valve replacement or pacemaker insertion. Additionally, no patient had postoperative ventricular arrhythmia. Eightyone patients were in sinus rhythm; the other 2 patients were in atrial fibrillation. Intraoperative transesophageal echocardiography after bypass showed that the tricuspid incompetence disappeared in 65 patients and was mild in 13. There was no tricuspid valve stenosis either. All these findings were confirmed on follow-up echocardiograms 7 days postoperatively, before the patient's discharge. Postoperative reduction in heart size was significant; the cardiothoracic ratio on chest radiograph had significantly decreased (mean, $0.63 \pm 0.07$ preoperatively vs $0.59 \pm 0.06$ postoperatively; $P<.01)$. Echocardiography before discharge showed that right ventricular cavity dimension was remarkably reduced (anteroposterior diameter, $41.3 \pm 8.6 \mathrm{~mm}$ preoperatively vs $24.3 \pm 5.3 \mathrm{~mm}$ postoperatively; $P<.01$ ), the atrialized chamber had vanished, and the three leaflets of the tricuspid valve were at the level nearing the natural annulus. After surgery, significant improvement in cardiac function was achieved in all patients.

Follow-up time ranged from 2 months to 9 years (46 \pm 12.5 months) in all patients. The improved cardiac function was maintained; 64 patients were in New York Heart Association functional class I, and the rest were in functional class II. Seventy-six patients were in sinus rhythm. At the most recent follow-up echocardiograms, tricuspid valve competence was sustained in 54 patients, and tricuspid incompetence was mild in 18 , moderate in 3 , and severe in 3. Right ventricular cavity dimension had a further decrease $(21.2 \pm 3.5 \mathrm{~mm}$ vs $24.3 \pm 5.3 \mathrm{~mm}$ postoperatively; $P<$ $.01)$. The 5 patients with the total cavopulmonary connection procedure and one-and-one-half-ventricle correction procedure are also doing well.

\section{Discussion}

The anatomic repair technique for the correction of Ebstein anomaly was successfully applied in 78 consecutive patients. Their excellent early and midterm results allow ex- 
tension of the scope of repair, even for patients previously deemed to require tricuspid valve replacement.

Ebstein anomaly is a complex congenital defect involving the tricuspid valve and right ventricle. The clinical presentation is closely related to the degree of tricuspid incompetence, right ventricular dysfunction, and associated lesions.

This technique of treating Ebstein anomaly differs from previous techniques $^{6-12}$ :

1. The atrialized ventricular wall is excised in the shape of a trapezoid or triangle. Therefore, the right ventricular geometry is restored, the atrialized ventricular chamber is completely obliterated, and the load on the right ventricle is alleviated. After surgery, the right ventricular cavity dimensions are restored to near normal, which is beneficial for the recovery of right ventricular function.

2. The displaced leaflets with their partial subvalvular structures are detached from their abnormal positions and reattached to a position near the true tricuspid annulus, and the new leaflet is made with autologous tissue if necessary. This technique improves the function and durability of "the new leaflets." It is important to reattach the septal leaflet strongly enough to avoid suture tear. Although fresh pericardial tissue is not a very satisfactory material to use for the reconstruction of septal leaflet, the leaflet was mobile and functioned well in most patients in this group during follow up.

3. There is less likelihood for the tricuspid annulus to enlarge after the annular plication with a 4-0 suture line because of the effective size reduction of the tricuspid annulus and the restoration of the valve leaflets to a near normal area and position, leading to competence of valve function.

It is important to avoid injury to the coronary arteries and the atrioventricular bundle during septal leaflet reattachment. In this series of patients, none had transient or permanent third-degree atrioventricular block. Our experience is to place the suture just below the atrioventricular bundle. The membranous interventricular septum can be viewed clearly.

For patients with a confirmed diagnosis of Ebstein anomaly, the indications for this procedure are as follows: the patient has symptoms, compromised heart function, moderate and above tricuspid regurgitation, and significantly enlarged right atrium and right ventricle. Most patients with Ebstein anomaly can avoid tricuspid valve replacement. Very few patients with very hypoplastic leaflets and severe dysfunction of the right ventricle may need one-and-onehalf-ventricle repair ${ }^{13}$ or some other procedures.

Because of complete excision of the atrialized ventricular wall, a trileaflet mechanism covering the entire orifice of the tricuspid valve and the restoration of the tricuspid annulus to its appropriate position and size, tricuspid valve competence is achieved. The incidence of right ventricular dysfunction and arrhythmia decreased significantly, thus yielding satisfactory early and midterm results after this procedure.

\section{References}

1. Boston US, Dearani JA, O'Leary PW, Driscoll DJ, Danielson GK Tricuspid valve repair for Ebstein's anomaly in young children: A 30-year experience Ann Thorac Surg. 2006;81:690-6.

2. Chen JM, Mosca RS, Altmann K, Printz BF, Targoff K, Mazzeo PA, et al., Early and medium-term results for repair of Ebstein anomaly. J Thorac Cardiovasc Surg. 2004;127:990-9.

3. Chauvaud S. Ebstein's malformation: surgical treatment and results. Thorac Cardiovasc Surg. 2000;48:220-3.

4. Chauvaud S, Berrebi A, d'Attellis N, Mousseaux E, Hernigou A, Carpantier A. Ebstein's anomaly: repair based on functional analysis. Eur J Cardiothorac Surg. 2003;23:525-31.

5. Wu Q, Huang Z. A new procedure for Ebstein's anomaly. Ann Thorac Surg. 2004;77:470-6.

6. Hardy KL, May IA, Webster CA, Kimball KG. Ebstein's anomaly: a functional concept and successful definite repair. J Thorac Cardiovasc Surg. 1964;48:927-40.

7. Danielson GK, Driscoll DJ, Mair DD, Warnes CA, Oliver WC Jr Operative treatment of Ebstein's anomaly. J Thorac Cardiovasc Surg. 1992;104:1195-202.

8. Carpentier A, Chauvaud S, Mace L, Relland J, Mihaileanu S, Marino JP, et al. A new reconstructive operation for Ebstein's anomaly of the tricuspid valve. J Thorac Cardiovasc Surg. 1988;96:92-101.

9. Quaegebeur JM, Sreeram N, Fraser AG, Bogers AJ,Stumper OF, Hess J, et al. Surgery for Ebstein's anomaly: the clinical and echocardiographic evaluation of a new technique. J Am Coll Cardiol. 1991;17: $722-8$.

10. Schmidt-Habelmann P, Meisner H, Struck E, Sebening F. Results of valvuloplasty for Ebstein's anomaly. J Thorac Cardiovasc Surg. 1981; 29:155-7.

11. Hetzer R, Nagdyman N, Ewert P, Weng YG, Alexi-Meskhisvili V, Berger F, et al. A modified repair technique for tricuspid incompetence in Ebstein's anomaly. J Thorac Cardiovasc Surg. 1998;115:857-68.

12. Vargas FJ, Mengo G, Granja MA, Gentile JA, Rannzini ME, Vazquez JC. Tricuspid annuloplasty and ventricular plication for Ebstein's malformation. Ann Thorac Surg. 1998;65:1755-7.

13. Alternative approach to repair of Ebstein's malformation: intracardiac repair with ventricular unloading. Ann Thorac Surg. 1998;66:1546-50.

\section{Discussion}

Dr Joseph A. Dearani (Rochester, Minn). I congratulate Dr Wu and his team for their excellent results in the surgical treatment of Ebstein anomaly. I have had the good fortune of visiting $\mathrm{Dr} \mathrm{Wu}$ in China and have observed him perform his repair. He is an innovative and gifted technical surgeon.

All of us are aware of the endless anatomic variability of Ebstein anomaly, and the literature documents a plethora of tricuspid valve repair techniques for this condition. This is the result of limitations and incomplete satisfaction with each of the repair methods available. In my opinion, the best way for the surgeon to optimize his or her ability to repair the Ebstein valve is to be familiar with all of the available techniques and to selectively apply principles and portions of the different techniques to the specific anatomy encountered in the operating room.

Dr Wu's method is a right ventricular remodeling method that incorporates tricuspid valve repair. I would point out one technical issue for those interested in applying this technique: always think 
about the right coronary artery when the annulus is plicated at the inferior angle. This can cause an acute angle in the natural circle of the atrioventricular groove and result in right coronary compromise, even though a suture does not actually go around the coronary artery.

$\mathrm{Dr} \mathrm{Wu}$, it is apparent from the manuscript and presentation that your patient population differs somewhat from our experience and from others reported in the literature. In your patient cohort, overall anatomic severity was not as complex. One third of your patients had just moderate tricuspid regurgitation. The anterior leaflet was well developed in two thirds of patients. Only one third of patients had an atrial septal defect or patent foramen ovale. Nevertheless, you have applied your technique successfully and have obtained excellent results in the vast majority of patients. Later detailed follow-up will be required to see whether the durability of this technique stands the test of time.

I have two questions. What anatomy do you consider not suitable for your technique? Perhaps some of these anatomic features were present in the 7 patients who required reoperation.

Dr Wu. Thank you very much for your very kind comments. I think that is a very good question. First, let's just think about it: if the function of the right ventricle is not very good after the operation, the patient cannot be weaned from cardiopulmonary bypass. How do we know that? We can know it from the echocardiogram and we can see during the operation. If the patient has a very big atrialized ventricle not functioning well, we have to do the total cavopulmonary connection procedure. This is especially true in some patients in whom the anterior leaflet is very severely hypoplastic and even downward into the right ventricular outflow tract, maybe nothing in the posterior and the septal leaflets. In some patients we need to do a one-and-one-half-ventricle repair. We judge according to the pathologic condition of the right ventricle. I think that is very important. Also, we look at the leaflets of the tricuspid valve to see whether there is enough tissue to make the new valve and to make the tricuspid valve competent. That is the key factor. We have one patient whose tricuspid valve was absent, in whom we inserted an artificial valve in the tricuspid valve position, with a very short cardiopulmonary bypass time, and finished the operation very quickly. However, the right ventricular function after the operation was not good and the patient died in the intensive care unit. I think the function of the ventricle is most important.

Dr Dearani. What has been your experience with the durability of a complete pericardial septal leaflet? Although the intraoperative transesophageal echocardiogram typically looks very good, I think most of us have found that the durability of complete pericardial leaflets is short-lived.

Dr Wu. We have to follow up the patients for a long time. At present, we have patients followed up to 7 and even 8 years. From echocardiography, we find the mobility of the septal leaflets is satisfactory. However, because most of the patients are children, one was even 9 months old, how long the leaflet function can remain satisfactory is a problem. For this procedure the most important part, as we know, is the anterior leaflet and then the posterior leaflet; the septal leaflet is not important. At the moment, what other material we can use? That's why we have to use pericardium to make the new septal leaflet, and then we must follow up the patient. That is my idea.
Dr Glen Van Arsdell (Toronto, Ontario, Canada). Professor $\mathrm{Wu}$, congratulations on that presentation. I too have had the privilege of seeing $\mathrm{Dr} \mathrm{Wu}$ do one of these operations and he's technically gifted and also, obviously, very creative.

The operation, as I see it, has three components: (1) ventricular resection, (2) a sliding leaflet plasty, and (3) creation of a septal leaflet with autologous pericardium.

At least in my hands, that third component is what is particularly interesting because it is posteriorly where we tend to see that regurgitant jet occur. Do you have any advice for us in terms of (1) how to construct that leaflet, (2) how to avoid the conduction tissue, and (3) whether to use fresh pericardium or glutaraldehyde?

Dr Wu. When we construct the leaflets, especially the posterior leaflet, we construct the leaflets before the plication of the annulus. To make the posterior leaflet very close to the anterior leaflet, you may need to slide the anterior leaflet posteriorly with strong enough sutures.

Regarding how to avoid damaging the atrioventricular bundle, we need to take care of that always. Usually in patients there is no septal leaflet and we can see the membranous ventricular septum. If we repair the ventricular septal defect, we know where the atrioventricular bundle may be and so we can avoid that. We put the suture just below that area to fix the base of the septal leaflet. In this group, none of our patients had atrioventricular block postoperatively.

Dr Van Arsdell. Are you still using fresh material or are you treating it with glutaraldehyde?

Dr Wu. We use fresh autologous pericardium, because it is soft and mobile. I have found that pericardial patches treated with glutaraldehyde are rigid.

Dr Van Arsdell. Let me just make sure I understand what you said. First, you make it generous, you attach it to the septal leaflet along the anterior leaflet margin, you look for a membranous septum to avoid the conduction tissue, and you use it fresh. Is that correct?

Dr Wu. Yes.

Dr Van Arsdell. For my second question, I noticed your youngest age at repair was 9 months. Can you elaborate about the younger children that you have operated on? I think most of us would find that a very interesting subset of patients because those are clearly the ones at highest risk.

Dr Wu. For younger patients, first I like to wait. However, if the patient has very severe tricuspid valve regurgitation and the right ventricle is enlarged quite significantly and the patient also has some symptoms, such as cyanosis, we may have to repair that in the earlier time. Also, we can use the fresh pericardium to make even two leaflets to make the valve competent. There are some other choices. The Glenn procedure can be done first and, in the future, maybe one-and-one-half-ventricle repair of the tricuspid valve.

Dr H. Capelli (Buenos Aires, Argentina). Congratulations on your impressive results. I wonder whether I should apologize for not making a surgical remark! It happens that I am just a pediatric cardiologist enjoying this prestigious thoracic surgeon's meeting.

You have shown a very nice postoperative echocardiographic picture depicting an impeccable result in terms of tricuspid valve competence. However, according to the large size of the right atrium and the turbulent right ventricular diastolic flow, it seems to 
me that the tricuspid valve has been left with some degree of stenosis. Has this patient had an enlarged liver or has he required diuretics after surgery? Was tricuspid stenosis a potential risk of this innovative surgical procedure?

Dr Wu. No, I don't think so. When we repair the valve, we always think about competence and stenosis of the valve. In this series, in a few patients we found some gradient that is acceptable. Also, the hemodynamic are very stable. Most of the patients do not need much medication.

Dr Antonio F. Corno (Liverpool, England). You mentioned 5 patients in whom you went for a univentricular type of repair or one-and-one-half-ventricle type of repair. Was this a preoperative decision based on some morphologic and/or functional element, or was this decision taken at the end of your procedure and you were unhappy with your result? If this happened, do you ever consider using a one-and-one-half-ventricle repair when you are unhappy at the end of the procedure?

Dr Wu. There were 4 patients in whom we made the decision preoperatively. In 1 patient we made the decision during the operation. We always prepare for one-and-one-half-ventricle repair in severe cases. After the repair, if the patient is okay, we send the patient to the intensive care unit. If there is some trouble, we re-evaluate and may then cut off the superior vena cava to do the Glenn procedure. That is my strategy.

Dr Christian Brizard (Melbourne, Australia). I have one small technical question. We use the same technique in Melbourne with excision of the atrialized portion of the right ventricle. How do you manage the top of the suture line next to the tricuspid valve annulus at the junction between the longitudinal suture line in the ventricle and the perpendicular plane of the tricuspid valve annulus? At that level, there is a triangular gap whose base is the tricuspid annulus at the posterior leaflet level. How do you manage that area precisely?

Dr Wu. I'm sorry. I couldn't catch your question clearly.
Dr Brizard. When you close the ventriculotomy, you have a longitudinal suture line and that goes perpendicular to the axis of the tricuspid valve annulus. When you are close to reach the tricuspid valve annulus, it is a technically difficult problem. How do you manage that?

Dr Wu. Usually I repair the leaflets first. After that, I do the plication of the annulus. That is very easy.

Dr Brizard. Do you compress the annulus after the reconstruction?

Dr Wu. Before the plication of the annulus we can measure how big the orifice size of the tricuspid valve is. Then we put in the suture line and leave it open. After valve repair, we do the plication of the annulus.

Dr Brizard. You excise the ventricle at the end?

Dr Wu. For the incision in the ventricle, we do it at the beginning. It is very easy to go to the top to close the tricuspid annulus.

Dr Brizard. So you limit your excision of the ventricle and stay far away from the tricuspid annulus?

Dr Wu. Yes, below the coronary arteries. The top end of the ventricular incision should be 1 to $2 \mathrm{~cm}$ below the coronary arteries.

Dr Andres J. Schlichter (Buenos Aires, Argentina). I congratulate $\mathrm{Dr} \mathrm{Wu}$ for his very nice technique and I was wondering if you had to treat some arrhythmias in your patients in this series? This is a big number and I was surprised to see there was no inclusion of treatment of arrhythmias or Wolff-Parkinson-White syndrome or similar conditions. If you do treat arrhythmias in these patients, when do you do it, before or after the tricuspid valve plasty?

Dr Wu. We have 2 patients with the Wolff-Parkinson-White syndrome, doing that before the operation. One patient had received a pericardial repair and was treated for severe WolffParkinson-White syndrome after the operation.

Dr Schlichter. So you do not do it intraoperatively? Dr Wu. No. 